\title{
MICROSTRUCTURE AND MECHANICAL PROPERTIES OF HIP PM 718
}

\author{
Ulrike Habel \\ Crucible Research Center \\ 6003 Campbells Run Road \\ Pittsburgh. PA 15205
}

USA

\begin{abstract}
This paper explores advantages of powder metallurgical $(\mathrm{P} / \mathrm{M})$ processing of Alloy 718 using gas atomization and hot isostatic pressing (HIP). To evaluate the effect of different processing parameters on HIP P/M 718, powders with low and standard carbon levels were produced by nitrogen and argon atomization. A small amount of $\mathrm{Mg}$ was added to one heat to investigate the possibility of improving elevated temperature properties. The Mg-treatment is a necessity to obtain good creep properties.

The consolidated materials are fully dense and have very fine and homogeneous microstructures typical for fully dense P/M alloys. Yield strength levels range from 140 to $170 \mathrm{ksi}$ at room temperature, and from 115 to $145 \mathrm{ksi}$ at $1200^{\circ} \mathrm{F}$. while tensile ductilities range form 19 to 15 and 9 to $24 \%$, respectively. Different heat treatments were evaluated, since the standard heat treatment for cast and wrought 718 led to heavy decoration of prior powder particle and grain boundaries. which resulted in low ductility. especially at $1200^{\circ} \mathrm{F}$. Creep rupture properties were evaluated at $1200^{\circ} \mathrm{F}$ and $100 \mathrm{ksi}$. Depending on heat treatment, time to rupture was as high as $170 \mathrm{hrs}$. Higher solution temperatures resulted in microstructures with less grain boundary decoration. better ductilities and improved creep properties with little loss in strength. During solutioning at $1800^{\circ} \mathrm{F}$. no grain growth was observed, and very limited grain growth was observed during heat treatments at temperatures up to $2200^{\circ} \mathrm{F}$. Taking into account the relatively low levels of precipitate forming elements, the strength levels are still fairly good.
\end{abstract}

Superalloys 718.625.706 and Various Derivatives

Edited by E.A. Loria

TMS (The Minerals. Metals \& Materials Society). 2001 


\section{Introduction}

Inert gas atomization is a powder production process used for a wide range of high performance metallic materials. For example. Ni- and Ni-Fe based P/M superalloys are used for aerospace applications. $\mathrm{P} / \mathrm{M}$ stainless steels for highly corrosive environments and $\mathrm{P} / \mathrm{M}$ tool steels for cutting, grinding and wear resistant materials [1], [2]. [3]. During gas-atomization rapid solidification occurs and suppress segregation. which translates into a simplified processing route. This is especially important for highly alloyed materials such as Alloy 718, which has a propensity for segregation due to high Nb-content [4], [5]. Alloy 718 is usually produced in the cast or cast and wrought $(\mathrm{C} / \mathrm{W})$ form. The $\mathrm{P} / \mathrm{M}$ route also uses less raw material as it allows near-net-shape production.

Investigations of helium atomized and direct extruded Alloy 718 found very fine grain sizes and good tensile properties compared to a $\mathrm{C} / \mathrm{W}$ alloy of the same composition [6]. [7]. It has been shown that in $\mathrm{P} / \mathrm{M}$ Alloy 718 the same phases are present as in $\mathrm{C} / \mathrm{W}$ Alloy 718 [8].

Focus areas of this study were carbon level, atomization gas, and magnesium treatments of the melt. In $\mathrm{P} / \mathrm{M}$ Ni-base superalloys, low C-levels are desirable, because they lead to cleaner powder particle surfaces and therefore to improved particle bonding during HIP. The use of nitrogen as atomization gas leads to cost savings compared to the use of argon. but can lead to N-uptake, which is potentially detrimental. Additions of $\mathrm{Mg}$ during melting of superalloys are known to improve elevated temperature tensile and creep properties [9]. [10]. [11], [12]. In addition. the effects of heat treatments on microstructure and mechanical properties were investigated.

\section{Experimental Procedure}

Fifty pound heats of Alloy 718 were made by $\mathrm{N}$ - and Ar-atomization in the LGA. The designations A718 and N718 refer to the argon and nitrogen atomized materials, respectively, with standard $\mathrm{C}$-content. The low-carbon versions contain as low as possible carbon levels and are designated N718LC and A718LC. For a second N718 heat. a Mg treatment was conducted after the charge was fully molten and before it was atomized. This heat is designated $\mathrm{N} 718(\mathrm{Mg})$. All powders were screened to -140 mesh, canned in mild steel, hot outgassed. sealed, and subsequently HIP'ed at $2065^{\circ} \mathrm{F}$ and $15 \mathrm{ksi}$ for $4 \mathrm{hrs}$.

Blanks for microstructural investigations and mechanical testing were subjected to three different solution heat treatments. Heat Treatment I, the standard heat treatment for C/W 718, consisted of 1 hour at $1800^{\circ} \mathrm{F}$ followed by furnace cooling. Heat treatments II and III consisted of 1 hour at 2000 and $2200^{\circ} \mathrm{F}$, respectively. After the solution heat treatment, air cooling is normally used. but furnace cooling of the small blanks was chosen here to simulate the slow cooling rate within a large workpiece such as a disk for power generation. Solution Treatments I, II, and III were followed by ageing for 8 hours at $1325^{\circ} \mathrm{F}$, furnace cooling to $1150^{\circ} \mathrm{F}$ plus ageing at 8 hours at $1150^{\circ} \mathrm{F}$ followed again by furnace cooling.

The as-atomized powders, the consolidated materials were investigated by optical microscopy, SEM (scanning electron microscope) and energy dispersive X-ray analysis (EDX). Samples for optical microscopy were prepared by electrolytic etching with a mixture of $10 \mathrm{ml}$ hydrochloric acid, $10 \mathrm{ml}$ methanol. and $1 \mathrm{ml}$ tartaric acid. For SEM investigations, electrolytic polishing with $20 \%$ sulfuric acid in methanol was applied. Tensile and Charpy impact tests were conducted according to ASTM E8 and E23, respectively. Creep tests were conducted at $1200^{\circ} \mathrm{F}$ and $100 \mathrm{ksi}$. 


\section{Chemical Composition}

All five $\mathrm{P} / \mathrm{M} 718$ versions have the same basic composition and differ only in $\mathrm{N}$-, $\mathrm{C}$ - and $\mathrm{Mg}$-levels (Table I). The combined $\mathrm{Nb}+\mathrm{Ti}+\mathrm{Al}$-content ranges from 6.04 to $6.58 \%$. This variation is mainly due to differences in $\mathrm{Nb}$-level, which varies between 4.70 and $5.18 \%$. The Ti/Al-ratio is 1.8 except for Alloys A718LC and N718LC, where it is 1.9 and 2.0, respectively.

For Alloys A718, A718LC, N718, and N718LC. the Mg-content is 10 wppm. while Alloy N718(Mg) contains a Mg-level of $70 \mathrm{wppm}$. The Ar-atomized powders contain 20 to $30 \mathrm{wppm}$ nitrogen. Some nitrogen pick-up occurred during $\mathrm{N}$-atomization leading to levels of 800 to 1000 wppm nitrogen. The C-levels range from 40 or $50 \mathrm{wppm}$ for the low-carbon heats to 110 or 120 wppm for the standard-carbon heats.

Table I Chemical composition of P/M 718 alloys (wt\%)

\begin{tabular}{||l|c|c|c|c|c|c|c|c|c|c|c|c||}
\hline Alloy & $\mathrm{Fe}$ & $\mathrm{Cr}$ & $\mathrm{Nb}$ & $\mathrm{Ti}$ & $\mathrm{Al}$ & $\mathrm{Mo}$ & $\mathrm{B}$ & $\mathrm{C}$ & $\mathrm{O}$ & $\mathrm{N}$ & $\mathrm{Mg}$ & $\mathrm{Ni}$ \\
\hline \hline Unit & \multicolumn{9}{|c|}{ Wt $\%$} & \multicolumn{6}{c|}{ Wppm } & \\
\hline \hline A718 & 18.13 & 17.91 & 4.80 & 0.88 & 0.48 & 2.95 & 46 & 110 & 132 & 30 & 10 & Bal. \\
\hline A718LC & 18.00 & 17.76 & 5.10 & 0.89 & 0.47 & 2.99 & 38 & 40 & 141 & 20 & 10 & Bal. \\
\hline N718 & 18.18 & 17.86 & 4.70 & 0.86 & 0.48 & 2.97 & 31 & 120 & 167 & 790 & 10 & Bal. \\
\hline N718LC & 18.14 & 17.86 & 5.15 & 0.90 & 0.46 & 2.91 & 36 & 40 & 105 & 820 & 10 & Bal. \\
\hline N718(Mg) & 18.15 & 17.80 & 4.84 & 0.88 & 0.49 & 2.97 & 35 & 120 & 111 & 980 & 70 & Bal. \\
\hline
\end{tabular}

Co. Mn, Cu: $\leq 100$ wppm; S $\leq 10$ wppm; P: 40 ... 60 wppm; Si $400 \ldots 600$ wppm

\section{Microstructure}

All $\mathrm{P} / \mathrm{M}$ versions of Alloy 718 exhibit very fine and homogeneous microstructures typical for gasatomized materials. The as-HIP P/M 718 alloys show varying degrees of prior particle and grain boundary outlining (Figure 1). Similarly, the $\mathrm{N}$-atomized variants exhibit a more pronounced powder particle boundary outlining than the Ar-atomized materials. The grain sizes in the as-HIP condition are around ASTM No. 8 [13]. They are coarser than for direct extruded Alloy 718 [7]. which is not surprising given the absence of recrystallization during HIP.

SEM investigations reveal information about the character of the precipitates found in P/M 718 . Backscatter electron images of as-HIP materials show black appearing spherical and elongated precipitates (Figures $1 \mathrm{~b}$ and $\mathrm{d}$ ). EDX analysis indicates that these are titanium carbo-nitrides. They are much more prevalent in Alloy N718LC than in Alloy A718 due to their different N-contents. The titanium carbo-nitrides rarely exceed $0.5 \mu \mathrm{m}$ in size for Alloy N718. For Alloy A718, they are usually less than $0.2 \mu \mathrm{m}$ in size, and there are significantly fewer of them.

Following Heat Treatment I, the standard heat treatment for C/W Alloy 718, needle-shaped precipitates decorate the grain boundaries (Figures $2 \mathrm{a}$ and $\mathrm{c}$ ). These precipitates appear bright in Backscatter electron images (Figures $2 \mathrm{~b}$ and $\mathrm{d}$ ). They are, according to EDX-analysis, $\mathrm{Ni}_{3}(\mathrm{Nb}, \mathrm{Ti})$. Their composition and their shape confirm that they are $\delta$-phase [14].

To reduce the grain boundary decoration, solution heat treatments were conducted at temperatures between 2000 and $2200^{\circ} \mathrm{F}$ followed by the standard ageing heat treatment. These higher solution 
temperatures reduced particle outlining significantly, but led only to a small increase in grain size (Figure 3). Grain sizes in the heat treated conditions range from 21 to $28 \mu \mathrm{m}$ [13]. For the Aratomized alloys. solution treating at $2000^{\circ} \mathrm{F}$ is sufficient to alleviate the grain and particle boundary outlining. while for the $\mathrm{N}$-atomized alloys at least $2200^{\circ} \mathrm{F}$ are required. Higher solution temperatures were not explored. as they are not practical in production.

In general. the $\mathrm{N}$-atomized materials have a somewhat finer grain size than their Ar-atomized counterparts. This is likely due to grain boundary pinning by titanium carbo-nitrides. The fine grain sizes observed after heat treating at temperatures well above the $\delta$-solvus temperature of $1850^{\circ} \mathrm{F}$ indicate that, for $\mathrm{P} / \mathrm{M}$ Alloy $718, \delta$-phase is not needed to pin grain boundaries. This agrees with observations by Merrick [6] as well as Radavich and Meyers [8]. In contrast. for C/W or cast Alloy $718 \delta$-phase is necessary to restrict grain growth [14].

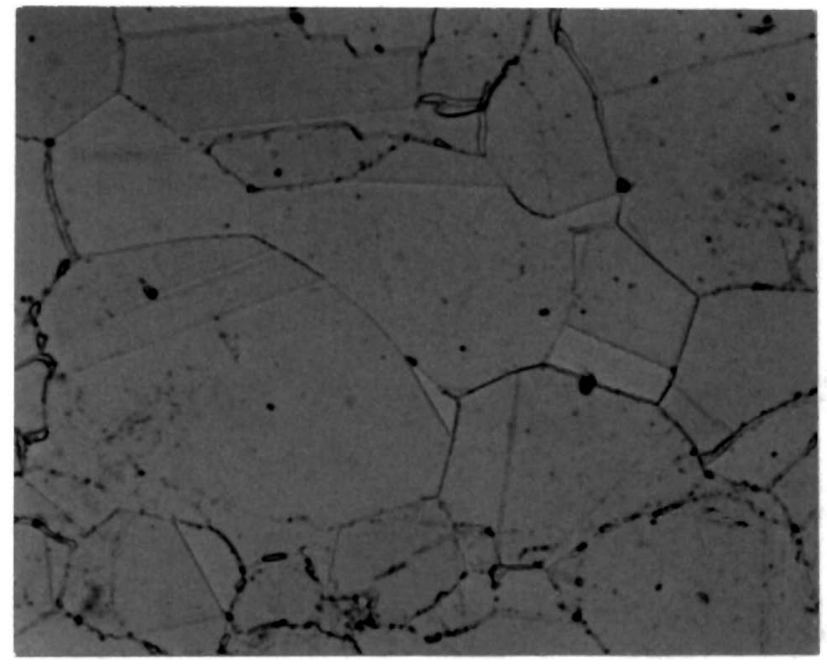

a)

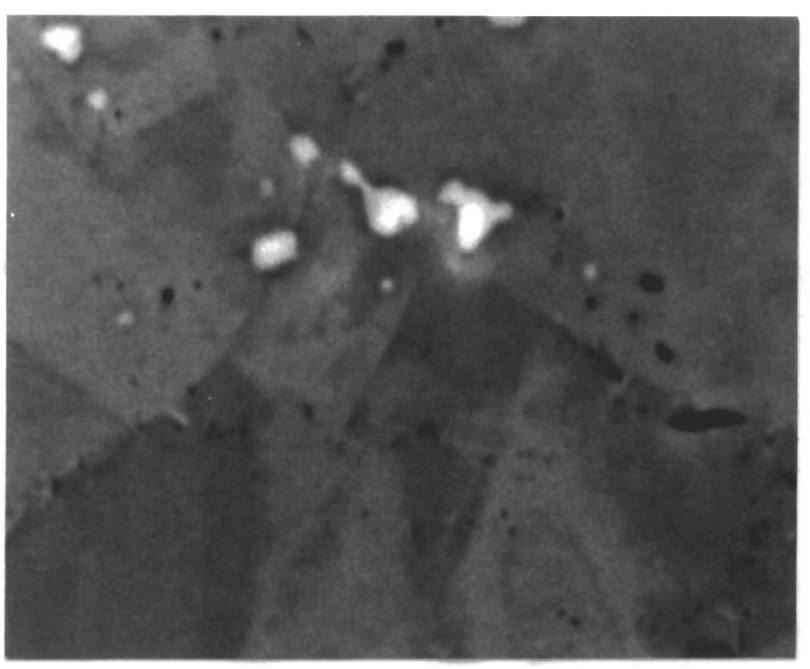

c) $\overline{10 \mu \mathrm{m}}$

$\overline{2 \mu \mathrm{m}}$

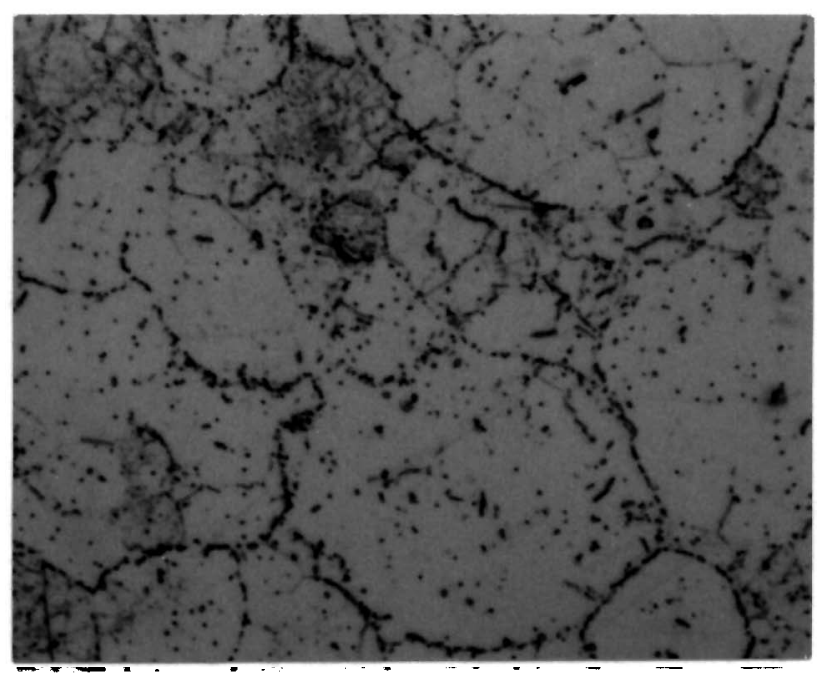

b)

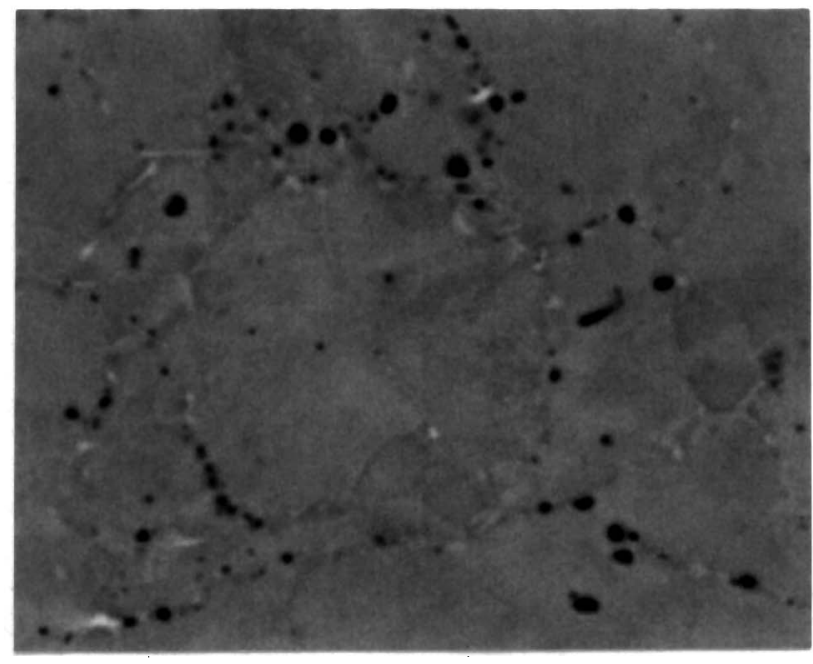

d) $\overline{2 \mu \mathrm{m}}$

Figure 1 Microstructure of as-HIP P/M 718

$\begin{array}{ll}\text { a), c) } \mathrm{A} 718 & \text { b), d) N718LC }\end{array}$ 


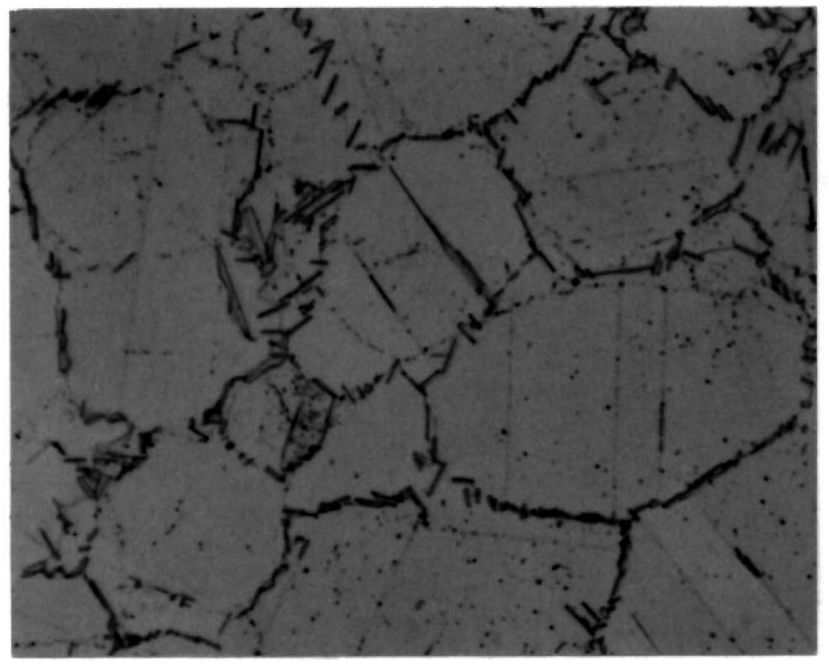

a)

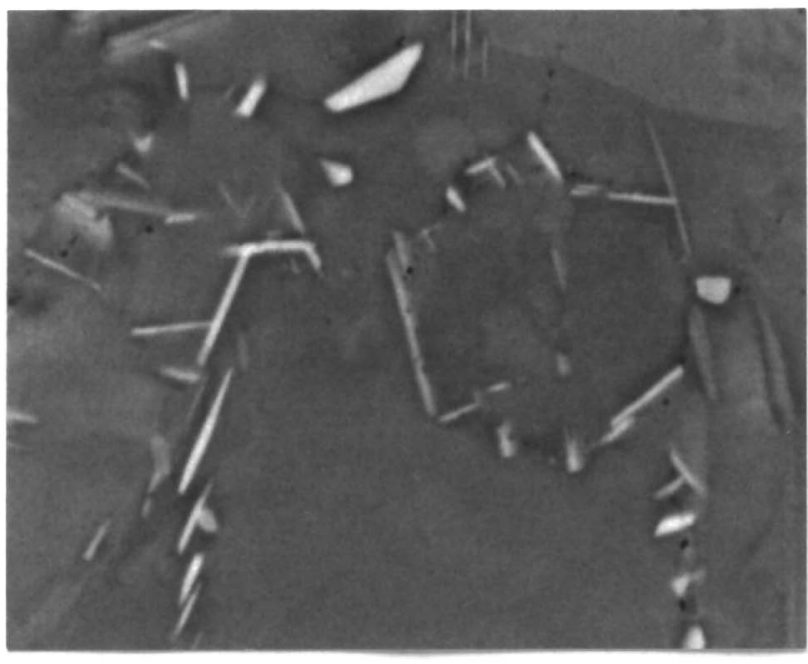

c) $\overline{10 \mu \mathrm{m}}$

$\overline{2 \mu \mathrm{m}}$

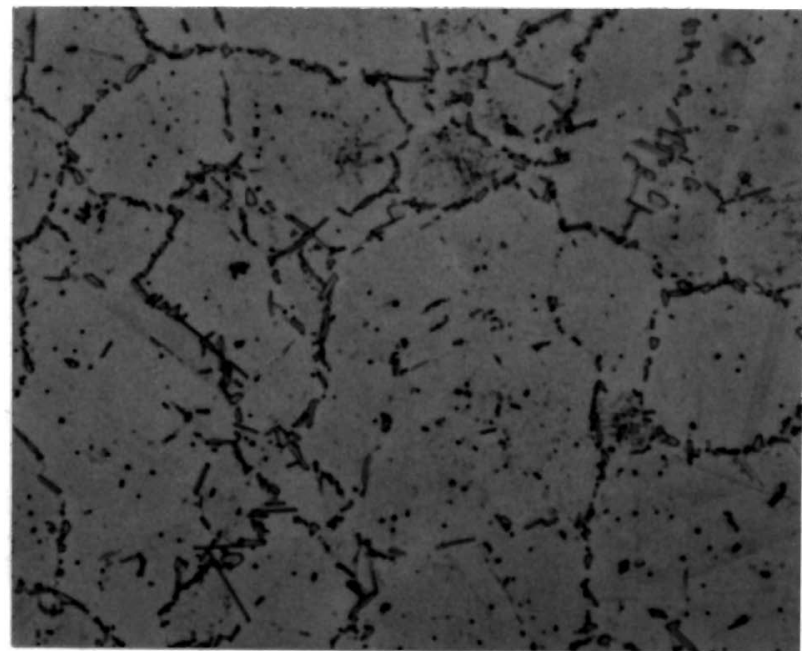

b)

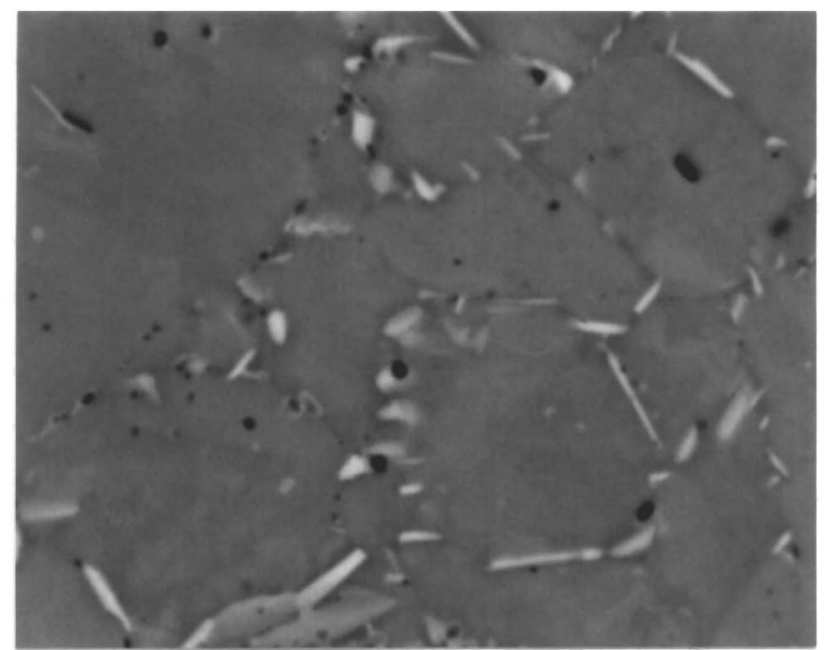

d) $\overline{2 \mu \mathrm{m}}$

Figure 2 Microstructure of $\mathrm{P} / \mathrm{M} 718$

a), c) $\mathrm{A} 718$

b). d) N718LC

Heat treatment I: $1 \mathrm{hr} 1800^{\circ} \mathrm{F}(\mathrm{FC})+8 \mathrm{hrs} 1325^{\circ} \mathrm{F}$. FC to $1150^{\circ} \mathrm{F}+$ age

\section{Tensile Properties}

The room temperature mechanical properties for Heat Treatment I are summarized in Table II. The yield strength ranges from $152 \mathrm{ksi}$ for Alloy A718LC to $163 \mathrm{ksi}$ for Alloy N718(Mg). The $\mathrm{N}$-atomized materials show higher yield stresses than their Ar-atomized counterparts. This difference can be attributed to compositional and microstructural difference. The presence of titanium carbo-nitrides observed in the alloys with higher nitrogen levels (Figure 2) suggests that additional sub- $\mu \mathrm{m}$ precipitates of the same type. whose size is below SEM resolution. could be present. Sub- $\mu \mathrm{m}$ titanium carbo-nitrides could contribute to the overall strength by dispersion 


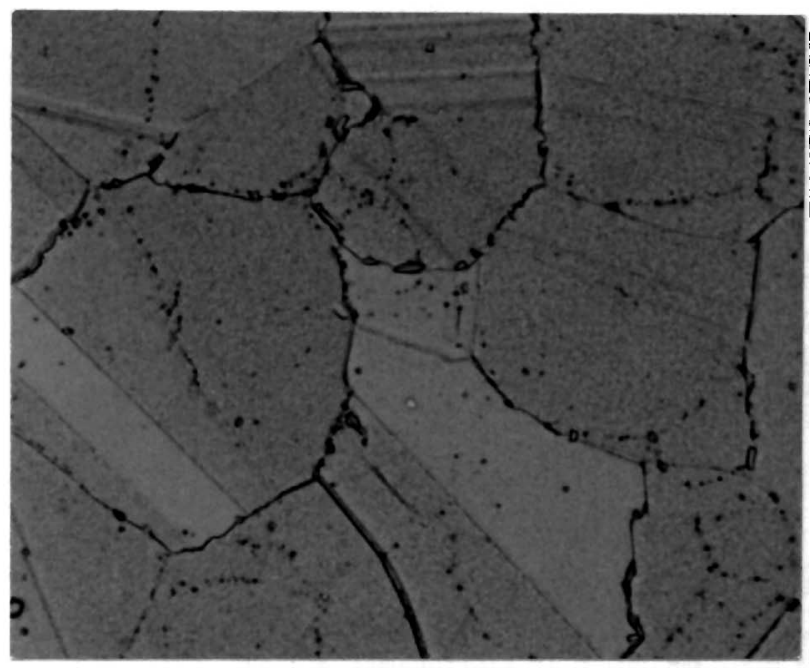

a)

$\overline{10 \mu \mathrm{m}}$

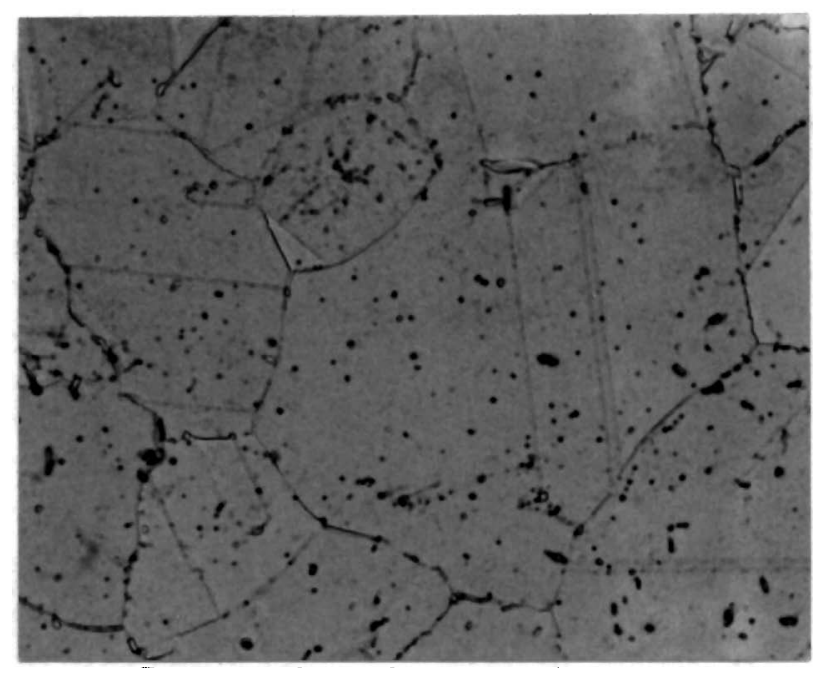

b)

$\overline{10 \mu \mathrm{m}}$

Figure 3 Microstructure $\mathrm{P} / \mathrm{M} 718$ a) A718. Heat treatment II: $1 \mathrm{hr} 2000^{\circ} \mathrm{F}(\mathrm{FC})+$ age

b) N718LC. Heat treatment III: $1 \mathrm{hr} 2200^{\circ} \mathrm{F}$ (FC) + age

Table II Tensile Properties of P/M 718: Heat Treatment I: $1 \mathrm{hr} 1800^{\circ} \mathrm{F}(\mathrm{FC})+$ age

\begin{tabular}{|l|c|c|c|c|c||}
\hline \hline Alloy/Specification & Temperature & YS $(\mathrm{ksi})$ & UTS $(\mathrm{ksi})$ & TE $(\%)$ & RA (\%) \\
\hline \hline A718 & Room & $152.8 \pm 1.1$ & $201.9 \pm 0.4$ & $20.3 \pm 3.0$ & $28.0 \pm 6.9$ \\
\hline A718LC & Room & $151.5 \pm 2.4$ & $200.6 \pm 0.7$ & $17.6 \pm 1.4$ & $21.4 \pm 2.3$ \\
\hline N718 & Room & $157.9 \pm 2.6$ & $203.0 \pm 2.9$ & $17.8 \pm 2.2$ & $21.4 \pm 2.2$ \\
\hline N718 LC & Room & $157.4 \pm 2.5$ & $202.5 \pm 1.5$ & $18.6 \pm 2.6$ & $26.8 \pm 4.4$ \\
\hline N718(Mg) & Room & $163.2 \pm 9.8$ & $203.7 \pm 3.5$ & $18.4 \pm 3.1$ & $22.0 \pm 3.6$ \\
\hline AMS 5662J & Room & 150 & 180 & $6^{*} \ldots 12^{*}$ & $8^{*} \ldots 15^{* *}$ \\
\hline A718 & $1200^{\circ} \mathrm{F}$ & $139.7 \pm 0.3$ & $161.3 \pm 2.1$ & $11.0 \pm 1.4$ & $15.0 \pm 0.5$ \\
\hline A718LC & $1200^{\circ} \mathrm{F}$ & $127.5 \pm 6.2$ & $164.0 \pm 1.0$ & $13.0 \pm 2.8$ & $13.0 \pm 4.2$ \\
\hline N718 & $1200^{\circ} \mathrm{F}$ & $137.1 \pm 9.3$ & $164.0 \pm 1.0$ & $10.5 \pm 0.7$ & $12.1 \pm 3.0$ \\
\hline N718 LC & $1200^{\circ} \mathrm{F}$ & $141.1 \pm 8.7$ & $157.6 \pm 5.8$ & $9.0 \pm 1.4$ & $12.1 \pm 1.3$ \\
\hline N718(Mg) & $1200^{\circ} \mathrm{F}$ & $133.6 \pm 10.0$ & $166.7 \pm 1.1$ & $11.0 \pm 4.2$ & $13.4 \pm 2.5$ \\
\hline AMS 5662J & $1200^{\circ} \mathrm{F}$ & 125 & 145 & $6^{*} \ldots 12^{* *}$ & $8^{*} \ldots 15^{* *}$ \\
\hline
\end{tabular}

$*$ transverse $* *$ longitudinal 
Table III Tensile Properties of P/M 718: Heat Treatment II: 1 hr $2000^{\circ} \mathrm{F}(\mathrm{FC})+$ age

\begin{tabular}{||l|c|c|c|c|c||}
\hline Alloy/Specification & Temperature & YS $(\mathrm{ksi})$ & UTS $(\mathrm{ksi})$ & TE $(\%)$ & RA $(\%)$ \\
\hline \hline A718 & Room & $142.1 \pm 3.1$ & $193.8 \pm 0.0$ & $24.3 \pm 0.0$ & $38.1 \pm 1.7$ \\
\hline A718 LC & Room & $138.6 \pm 0.3$ & $193.3 \pm 0.3$ & $18.6 \pm 2.1$ & $24.1 \pm 1.1$ \\
\hline AMS 5662.J & Room & 150 & 180 & $6^{*} \ldots 12^{* *}$ & $8^{*} \ldots 15^{* *}$ \\
\hline A718 & $1200^{\circ} \mathrm{F}$ & $118.6 \pm 1.1$ & $155.6 \pm 0.6$ & $21.5 \pm 2.1$ & $26.4 \pm 2.1$ \\
\hline A718 LC & $1200^{\circ} \mathrm{F}$ & $117.2 \pm 1.6$ & $155.6 \pm 0.0$ & $23.6 \pm 1.0$ & $25.8 \pm 1.2$ \\
\hline AMS 5662J & $1200^{\circ} \mathrm{F}$ & 125 & 145 & $6^{*} \ldots 12^{* *}$ & $8^{*} \ldots 15^{* *}$ \\
\hline
\end{tabular}

* transverse ** longitudinal

hardening. This would have to be verified by TEM. Also, solution hardening of the $\gamma$-matrix by nitrogen on interstitial sites seems likely. The room temperature tensile elongations are around $20 \%$ for all versions. Similarly, the reductions of area are between 19 and $28 \%$. All specimens exhibit similar ultimate tensile strength (UTS) levels. just above $200 \mathrm{ksi}$. except for Alloy N718LC(Mg).

At $1200^{\circ} \mathrm{F}$, the yield strength after Heat Treatment I varies between 128 and $141 \mathrm{ksi}$ as shown in Table II. The UTS levels range from 158 to $164 \mathrm{ksi}$. The tensile elongations range from 9 to $13 \%$. the reductions of area from 12 to $15 \%$. Again, the N-atomized materials show lower ductilities than the corresponding Ar-atomized materials. The ductility at $1200^{\circ} \mathrm{F}$ is less than at room temperature. This is not an unusual observation and is attributed to the transition from low temperature to high temperature deformation mechanisms [8]. [15]. [16]. At $1200^{\circ} \mathrm{F}$, the strength levels meet or exceed the values required by Aerospace Materials Specification (AMS) 5662J. while the ductilities. especially for the $\mathrm{N}$-atomized materials, are lower than the AMS $5662 \mathrm{~J}$ criteria.

Heat Treatments II and III increases ductility while slightly reducing strength ( Tables III and IV). This is in agreement with results of Merrick [6] as well as Radavich and Meyers [8]. The Natomized alloys exhibit room temperature yield strengths around $153 \mathrm{ksi}$. This decrease in strength compared to Heat Treatment $\mathrm{I}$ is most likely due to the increase in grain size. The decrease in strength is more pronounced in the Ar-atomized materials. Both Alloy A718 and Alloy A718LC show a room temperature yield strength of $144 \mathrm{ksi}$. The room temperature ductilities improve slightly: tensile elongations increase to 18 to $25 \%$. reductions of area improve to values from 24 to $39 \%$.

Again, the ductility at $1200^{\circ} \mathrm{F}$ is less than at room temperature, but it is drastically improved compared to Heat Treatment I. Tensile elongations are between 15 and $24 \%$ for most conditions. The exception is Alloy N718, which shows only 12\%. Yield strengths range from $117 \mathrm{ksi}$ for Alloy A718LC to $136 \mathrm{ksi}$ for Alloy N718LC. but Alloy N718(Mg) shows a very low yield stress of 100 $\mathrm{ksi}$. It is unclear. why the yield stress of Alloy $\mathrm{N} 718(\mathrm{Mg})$ is so low. All tensile properties except the yield stress of the Ar-atomized alloys and Alloy N718(Mg) and the reduction of area of the $\mathrm{N}$-atomized alloys not treated with $\mathrm{Mg}$ meet or exceed the AMS 5662J requirements. The UTS surpasses the requirement of AMS $5662 \mathrm{~J}$.

Heat treatments II and III result in fairly balanced tensile properties for Alloys A718 and N718LC. Overall. the properties are inferior compared to those reported by Flinn et al. for PM 718 [7]. mostly due to the finer grain size in the direct extruded material. 
Table IV Tensile Properties of P/M 718: Heat Treatment III: $1 \mathrm{hr} 2200^{\circ} \mathrm{F}(\mathrm{FC})+$ age

\begin{tabular}{||l|c|c|c|c|c||}
\hline Alloy/Specification & Temperature & YS (ksi) & UTS (ksi) & TE $(\%)$ & RA (\%) \\
\hline \hline A718 & Room & $143.9 \pm 0.5$ & $196.4 \pm 0.1$ & $25.5 \pm 0.9$ & $38.6 \pm 3.4$ \\
\hline A718LC & Room & $143.3 \pm 1.2$ & $196.0 \pm 0.8$ & $22.3 \pm 2.5$ & $26.8 \pm 4.5$ \\
\hline N718 & Room & $150.9 \pm 2.3$ & $195.8 \pm 4.6$ & $17.5 \pm 7.0$ & $25.3 \pm 7.6$ \\
\hline N718LC & Room & $152.7 \pm 2.6$ & $200.2 \pm 1.0$ & $24.7 \pm 0.6$ & $38.7 \pm 4.2$ \\
\hline N718(Mg) & Room & $153.8 \pm 5.4$ & $200.1 \pm 3.3$ & $22.3 \pm 0.5$ & $31.8 \pm 6.4$ \\
\hline AMS 5662J & Room & 150 & 180 & $6^{*} \ldots 12^{* *}$ & $8^{*} \ldots 15^{* *}$ \\
\hline A718 & $1200^{\circ} \mathrm{F}$ & $126.5 \pm 2.0$ & $163.1 \pm 2.2$ & $19.5 \pm 3.5$ & $19.1 \pm 1.2$ \\
\hline A718LC & $1200^{\circ} \mathrm{F}$ & $117.5 \pm 9.3$ & $160.8 \pm 0.1$ & $15.5 \pm 0.7$ & $17.3 \pm 0.1$ \\
\hline N718 & $1200^{\circ} \mathrm{F}$ & $133.0 \pm 0.0$ & $163.9 \pm 0.6$ & $12.0 \pm 1.4$ & $13.8 \pm 0.0$ \\
\hline N718LC & $1200^{\circ} \mathrm{F}$ & $135.8 \pm 2.5$ & $162.5 \pm 0.4$ & $17.0 \pm 2.8$ & $13.4 \pm 2.6$ \\
\hline N718(Mg) & $1200^{\circ} \mathrm{F}$ & $100.2 \pm 4.4$ & $163.8 \pm 0.0$ & $15.5 \pm 2.1$ & $15.4 \pm 1.6$ \\
\hline AMS 5662J & $1200^{\circ} \mathrm{F}$ & 125 & 145 & $6^{*} .12^{* *}$ & $8^{*} \ldots 15^{* *}$ \\
\hline
\end{tabular}

* transverse ** longitudinal

In general. the $\mathrm{N}$-atomized alloys show greater strength. while the Ar-atomized alloys show better ductility. but there is no evidence that low-carbon versions perform better or worse than the standard-carbon versions. Also, no correlation could be found between the content of precipitation hardening elements. $\mathrm{Nb}$. Ti. and $\mathrm{Al}$, and strength within the range of variation occurring here.

Incidentally, all LC alloys contain about $0.3 \%$ less $\mathrm{Nb}$ than the standard-carbon conditions. Nb is a $\delta$ - and $\gamma$ "- former, and generally a higher Nb-content translates in higher strength and lower ductility due to higher levels of $\delta$ - and $\gamma^{\prime \prime}$-phases. Therefore. an increase in ductility due to the lower carbon levels, if it was large enough to be measured, could be masked by a ductility loss resulting from the higher Nb-levels. Conversely, a decrease in strength due to the lower carbon levels, again if it was large enough to be measured. could be masked by an increase in strength resulting from the higher $\mathrm{Nb}$-levels. Investigations of $\mathrm{C} / \mathrm{W}$ Alloy 718 found no detrimental effect when the C-level was reduced from 270 to 80 wppm [17], [18].

The results of the tensile tests indicated that higher solution temperatures are needed for PM 718. $2000^{\circ} \mathrm{F}$ for Ar-atomized Alloy 718 and $2200^{\circ} \mathrm{F}$ for $\mathrm{N}$-atomized Alloy 718 . Further improved tensile properties could be expected from the use of faster cooling. especially after solution heat treatment [19]. In this study, furnace cooling was purposely employed to simulate the lower cooling rate in larger work pieces.

For applications which require high strength, a high-alloyed version of Alloy 718 is used. whose contents of Nb, Ti. Al. and Mo are at the upper limit of the specification [20]. It is known that this increases strength, but with a penalty in ductility [21], [22]. In this study, the aims for Ti and A1 were set conservatively to the average between maximum and minimum specified levels, while the $\mathrm{Nb}$-aim was $5.0 \%$ at a range of 4.75 to $5.50 \%$ (Table I). Taking the lower Nb-level into account. the strength levels achieved here are fairly good. 


\section{Creep Properties}

The creep rupture properties vary considerably with heat treatment and N-level. Still, the results should be interpreted with caution as material constraints allowed only one sample per condition.

After Heat Treatment I, the creep properties are very poor as shown in Table V. Ductilities are less than $2 \%$ except for Alloy $718(\mathrm{Mg})$, which exhibits $2.6 \%$. Times to rupture for smooth specimens range from 20 hrs for Alloy N718LC to 78 hrs for Alloy N718. The notched specimens fail prior to the smooth specimens indicating notch sensitivity after this heat treatment.

Heat treatments II and III were conducted to alleviate the prior particle and grain boundary decoration and to improve ductility and toughness. After Heat Treatments II and III. Alloys A718 and $\mathrm{A} 718 \mathrm{LC}$ are not notch sensitive and show times to rupture of 60 to $170 \mathrm{hrs}$ combined with an elongation of $4.8 \%$ meeting the AMS 5662J requirements of $23 \mathrm{hrs}$ and $4 \%$, respectively. In contrast. Alloys N718, N718(Mg) and N718LC are notch sensitive even after Heat Treatment III. Alloy $\mathrm{N} 718$ also fails below the time to rupture and elongation requirements.

Alloy $\mathrm{N} 718(\mathrm{Mg})$ exhibits longer time to rupture and higher creep ductility compared to Alloy N718 for both heat treatments (Tables IV and VI). It also shows somewhat higher tensile ductilities at $1200^{\circ} \mathrm{F}$ (Tables II and IV).

Notch sensitivity in Alloy 718 has been attributed to the presence of carbide films or very closely spaced $\delta$-phase precipitates, which weaken grain boundaries [23]. In P/M 718, higher solution temperatures can avoid the precipitation of relatively coarse $\delta$-precipitates without undue grain growth. Also, the notch sensitivity of direct extruded P/M 718 was shown to be overcome by a modified heat treatment. A step at intermediate temperature after solutioning and before ageing led to the formation of fine, acicular $\delta$-phase and, as a consequence, serrated grain boundaries. which counteract grain boundary sliding [6]. This route could not be explored during the present study due to lack of material.

Table V Creep Rupture Properties of $\mathrm{P} / \mathrm{M} 718$ tested at $1200^{\circ} \mathrm{F}, 100 \mathrm{ksi}$, one test per condition. Heat Treatment I: 1 hr $1800^{\circ} \mathrm{F}(\mathrm{FC})+$ age

\begin{tabular}{|l|c|c|c|c||}
\hline \hline Alloy/Specification & Specimen Type & Time to Rupture & Elongation & Reduction of Area \\
\hline \hline A718 & smooth & 47 & 0.8 & 4.8 \\
\hline A718 & notched & 14 & - & - \\
\hline A718LC & smooth & 61 & 1.6 & 5.6 \\
\hline A718LC & notched & 9 & - & - \\
\hline N718 & smooth & 78 & 1.6 & 5.6 \\
\hline N718 & notched & 1 & - & - \\
\hline N718LC & smooth & 20 & 1.6 & 5.6 \\
\hline N718LC & notched & 1 & & 6.7 \\
\hline N718(Mg) & smooth & 38 & 2.6 & - \\
\hline N718(Mg) & notched & 4 & - & - \\
\hline AMS 5662J & smooth/notched & 23 & 4.0 & \\
\hline
\end{tabular}


Heat treatments II and III increased ductility and creep rupture life as intended, but degraded the yield stress. Alloys based on N718 show superior strength but are notch sensitive, so they would be the preferred material for applications where high strength is required and creep is less important. A718-type alloys on the other hand are suited more for applications which demand good creep properties and a slightly lower strength can be tolerated. The data collected in this study do not show a performance advantage for either the standard-carbon or the low-carbon version, but they do show a necessity for a Mg-treatment.

Table VI Creep Rupture Properties of $\mathrm{P} / \mathrm{M} 718$ tested at $1200^{\circ} \mathrm{F}, 100 \mathrm{ksi}$, one test per condition. Heat Treatment II: $1 \mathrm{hr} 2000^{\circ} \mathrm{F}$ (FC) + age

\begin{tabular}{||l|c|c|c|c||}
\hline \hline Alloy/Specification & Specimen Type & Time to Rupture & Elongation & Reduction of Area \\
\hline \hline A718 & smooth & 32 & 5.2 & 11.2 \\
\hline A718 & notched & 128 & - & - \\
\hline A718LC & smooth & 67 & 7.9 & 11.2 \\
\hline A718LC & notched & 125 & - & - \\
\hline AMS 5662J & smooth/notched & 23 & 4.0 & - \\
\hline
\end{tabular}

Table VII Creep Rupture Properties of P/M 718 tested at $1200^{\circ} \mathrm{F}, 100 \mathrm{ksi}$, one test per condition. Heat Treatment III: $1 \mathrm{hr} 2200^{\circ} \mathrm{F}(\mathrm{FC})+$ age

\begin{tabular}{||l|c|c|c|c||}
\hline \hline Alloy/Specification & Specimen Type & Time to Rupture & Elongation & Reduction of Area \\
\hline \hline A718 & smooth & 82 & 4.8 & 10.0 \\
\hline A718 & notched & 169 & - & - \\
\hline A718LC & smooth & 63 & 4.8 & 11.2 \\
\hline A718LC & notched & 80 & - & - \\
\hline N718 & smooth & 75 & 1.6 & 6.4 \\
\hline N718 & notched & 9 & - & - \\
\hline N718LC & smooth & 61 & 4.0 & 9.8 \\
\hline N718LC & notched & 26 & - & - \\
\hline N718(Mg) & smooth & 90 & 4.3 & 7.5 \\
\hline N718(Mg) & notched & 25 & - & - \\
\hline AMS 5662J & smooth/notched & 23 & 4.0 & - \\
\hline
\end{tabular}




\section{Conclusions}

P/M 718 alloys with standard and reduced carbon levels were produced by argon and nitrogen atomization. They are fully dense and have a very fine and homogeneous microstructure. The P/M 718 versions are very resistant to grain growth during heat treatments up to $2200^{\circ} \mathrm{F}$.

Heat Treatment I $\left(1800^{\circ} \mathrm{F}\right.$ solution treatment), the standard heat treatment for $\mathrm{C} / \mathrm{W}$ Alloy 718 leads to heavy decoration of prior powder particle and grain boundary outlining in P/M 718. After Heat Treatment I, high strength levels and good ductilities are observed at room temperature. while at $1200^{\circ} \mathrm{F}$. low ductilities are combined with high strength levels.

The higher solution temperatures of Heat Treatments II and III $\left(2000\right.$ and $2200^{\circ} \mathrm{F}$ solution treatment, respectively) solve the problem of prior particle and grain boundary decoration for $\mathrm{Ar}$ and $\mathrm{N}$-atomized alloys. Heat Treatments II and III result in higher ductilities. especially at $1200^{\circ} \mathrm{F}$ and somewhat lower yield stress levels. Taking into account the relatively low levels of precipitate forming elements. the strength levels are still fairly good.

The Mg-treatment is a necessity to obtain good creep properties. An intermediate heat treatment step should be explored to reduce notch sensitivity in creep. Improved tensile properties can be expected from the use of faster cooling. especially after the solution heat treatment.

\section{Acknowledgments}

Special thanks are due to C.E. Rader, R.J.Hoffman, D.L. Franetti, M.W.Peretti, S.T. Roettger. J.R. Zurchin, R.M. Berg, and J.E. McCalla for their experimental assistance and to B.J. Mc Tiernan. J.H. Moll and J.J. Conway for technical discussions.

\section{Disclaimer}

The material contained herein is intended for general information only and should not be used in relation to any specific application without independent study and determination of its applicability and suitability for the intended application. In some cases. a complete evaluation of performance is not possible without more extended tests over longer time periods. Anyone making use of this material or relying thereon assumes all risk and liability arising therefrom.

\section{References}

[1] G.O. Rhodes and J.J. Conway. JOM. 48 (1996). 28-31

[2] U. Habel, F.J. Rizzo. J.J. Conway, R. Pishko, V.M. Sample and G.W. Kuhlman, in: Superalloys 718.625.706 and Various Derivatives, Ed. E.A. Loria, TMS, 1997, 245-256

[3] W. Stasko. K.E. Pinnow and R.B. Dixon, in: Advanced Particulate Materials and Processes. (Princeton, NY: Metal Powder Industries Federation, 1997), 401-409.

[4] R.C. Schwant, S.V. Thamboo, A.F. Anderson. C.B. Adasczik. B.J. Bond, L.A. Jackman and J.F. Uginet, in: Proc. of the International Symposium on Superalloys 718.625.706 and Various Derivatives, ed. E.A. Loria (Warrendale, PA: TMS, 1997). pp. 141-152

[5] A.S. Watwe. J.M. Hyzak and D.M. Weaver, in Proc. of the International Symposium on Superalloys 718.625.706 and Various Derivatives, ed. E.A. Loria (Warrendale, PA: TMS, 1997). pp. 237-246 
[6] H.F. Merrick. Met. Trans. A (1976), Vol. 7A, No. 4. pp. 505-514

[7] J. E. Flinn, K. Shin. and T. F. Kelly, in: Superalloys 718.625 and Various Derivatives. ed. E.A. Loria (Warrendale, PA: TMS, 1991), 251-260.

[8] J.F. Radavich, D.J Meyers, in: Superalloys 1984, eds. M. Gell. C.S. Kortovich, R.H. Bricknell. W.B. Kent. J.F. Radavich. (Warrendale, PA: AIME 1984), pp. 347-356

[9] D.R. Muzyka and C.R. Whitney, US Patent No. 3,575,734.

[10] P. Ma, Y. Yuan, and Z. Zhong. in: Superalloys 1988, eds. S. Reichman. D. N. Duhl, G. Maurer, S. Antolovich, and C. Lund (The Metallurgical Society, 1988), pp. 625-633.

[11] A. Mitchell, M. Hilborn, E. Samuelsson. and A. Kanagawa, in: Superallovs 1988. eds. S. Reichman. D. N. Duhl. G. Maurer. S. Antolovich, and C. Lund (The Metallurgical Society, 1988). 407-416.

[12] X. Xie. Z. Xu. B. Qu, G. Chen. and J. F. Radavich, in: Superalloys 1988, eds. S. Reichman. D. N. Duhl, G. Maurer, S. Antolovich, and C. Lund (The Metallurgical Society, 1988), 635-642.

[13] U. Habel and F.J. Rizzo, in: Advances in Powder Metallurgy and Particulate Materials, eds. C.L. Rose and M.H. Thibodeau. (Princeton. NY: Metal Powder Industries Federation 1999), Vol. 2. $4-135-4-144$

[14] C.T. Sims, N.S. Stoloff, W.C. Hagel, Superalloys II, (New York. NY: John Wiley and Sons. 1987). pp. $165-187$

[15] "Nickel Base Alloys", INCO, $2^{\text {nd }}$ ed., 1968

[16] E. Shapiro and G.E. Dieter, Met. Trans. 1A, pp. 1711-1719

[17] J.M. Moyer, in: Superalloys 1984, eds. M. Gell, C.S. Kortovich, R.H. Bricknell, W.B. Kent. J.F. Radavich, (Warrendale. PA: AIME 1984), pp. 443-454

[18] L. A. Jackman, M. D. Boldy, and A. L. Coffey, in: Superalloys 718, 625 and Various Derivatives. ed. E. A. Loria (Warrendale. PA: TMS, 1991), pp. 261-270.

[19] J.J. Schirra, in: Proc. of the International Symposium on Superalloys 718.625.706 and Various Derivatives, ed. EA. Loria (Warrendale, PA: TMS, 1997), pp. 431-438

[20] D.D. Krueger, in Proc. of the International Symposium on Superalloy 718, ed. EA. Loria (Warrendale, PA: TMS, 1989), pp.279 - 295

[21] H.I. Eiselstein. ASTM STP No. 369. 1965. pp. 62-79

[22] S. Mannan. S. Patel, and J. DeBarbadillo, in: Superalloys 2000, eds.T.M. Pollock. R.D. Kissinger, R.R. Bowman. K.A. Green. M. McLean. S. Olson. and J.J. Schirra, (Warrendale, PA: TMS, 2000), pp. 449-458

[23] G. Sjoberg, N.-G. Ingesten, in: Superalloys 718.625 and Various Derivatives. ed. E. A. Loria (Warrendale, PA: TMS, 1991), pp. 603-620 